Article

\title{
Equity Option Pricing with Systematic and Idiosyncratic Volatility and Jump Risks
}

\author{
Zhe Li \\ Business School, Nanjing Normal University, Nanjing 210023, China; zheli@njnu.edu.cn
}

Received: 21 November 2019; Accepted: 12 January 2020; Published: 17 January 2020

\begin{abstract}
Recently, a large number of empirical studies indicated that individual equity options exhibit a strong factor structure. In this paper, the importance of systematic and idiosyncratic volatility and jump risks on individual equity option pricing is analyzed. First, we propose a new factor structure model for pricing the individual equity options with stochastic volatility and jumps, which takes into account four types of risks, i.e., the systematic diffusion, the idiosyncratic diffusion, the systematic jump, and the idiosyncratic jump. Second, we derive the closed-form solutions for the prices of both the market index and individual equity options by utilizing the Fourier inversion. Finally, empirical studies are carried out to show the superiority of our model based on the S\&P 500 index and the stock of Apple Inc. on options. The out-of-sample pricing performance of our proposed model outperforms the other three benchmark models especially for short term and deep out-of-the-money options.
\end{abstract}

Keywords: equity option pricing; factor models; stochastic volatility; jumps

JEL Classification: G13

\section{Introduction}

Most of the existing literature studies on option pricing are for index options, and there are very few about equity options. One approach to modeling equity options is to employ the state-of-the-art model in the index option literature, a stochastic volatility model with jumps (see, for example, Bates 1996, 2000; Bakshi et al. 1997; Duffie et al. 2000; Eraker et al. 2003; Broadie et al. 2007; Christoffersen et al. 2012; Andersen et al. 2015; Bardgett et al. 2019), but to ignore any underlying factor structure.

In Bakshi and Kapadia (2003a), the research results indicated that the volatility risk premium is negative in index options by examining the statistical properties of delta hedged option portfolios, i.e., a portfolio of a long call option position hedged by a short position in the stock. On the one hand, stock returns have a significant market component; the emergence of market volatility risk premiums is bound to have an impact on individual equity option pricing. On the other hand, from the economic point of view, the risk neutral distributions of individual equities are systematically different from the market index. Thus, it is necessary to explore how volatility risk is priced in individual equity options, which also can produce additional insights into the pricing structure of individual equity options (see Bakshi et al. 2003). As is well known, the beta of a stock represents the sensitivity of the risk of the individual equity with respect to the systematic risk of the market and is very useful for portfolio construction in the capital asset pricing model. Therefore, under the assumption that stock returns include a market component and an idiosyncratic component, Bakshi and Kapadia (2003b) developed a factor model for equity option valuation and investigated the pricing of market volatility risk in individual equity options. Their empirical results showed that volatility risk premiums in equity options are smaller than in index options. 
Afterwards, Fouque and Kollman (2011) proposed a continuous-time capital asset pricing model (CAPM) where the dynamics of the market index have a stochastic volatility driven by a fast mean reverting process. Moreover, they derived the analytical approximation pricing formulas for both the market index and individual equity call options using a singular perturbation method. Meanwhile, a calibration method for the beta parameter was also presented based on the estimated model parameters of both the market index and individual equity option prices. Subsequently, Fouque and Tashman (2012) extended the constant beta-parameter factor model of Fouque and Kollman (2011) by considering a piecewise-linear relationship between the individual asset and the market index and proposed a regime switching factor model for the pricing market index and individual equity options. Supposing that stock return is linearly related to market index return in terms of the beta parameter, Carr and Madan (2012) developed a factor model for individual equity option pricing under a purely discontinuous Lévy process via fast Fourier transform, in which the variance gamma process for the dynamics of both the market index and stock was taken as an example for illustration. By supposing a continuous-time CAPM with Lévy processes, Wong et al. (2012) also derived analytical solutions to the index and equity options and explored the corresponding static hedging with index futures. Christoffersen et al. (2018) empirically studied the equity volatility levels, skews, and term structures by using equity option prices and principal component analysis. The results indicated that the equity options had a strong factor structure, and then, they developed an equity option pricing model with a CAPM factor structure and stochastic volatility, which allowed for mean reverting stochastic volatility for the dynamics of both the market factor and individual equity.

Recently, Xiao and Zhou (2018) proposed a GARCH-jump model for individual stock returns that took into account four types of risks: the systematic and idiosyncratic jumps and the systematic and idiosyncratic diffusive volatility. By using a dataset consisting of the S\&P 500 index and 15 individual stock prices, their empirical results indicated that idiosyncratic jumps were a key determinant of expected stock return. ${ }^{1}$ Instead of using only stock returns, Kapadia and Zekhnini (2019) used both stock and option data to decompose the four risk premiums associated with systematic and idiosyncratic diffusive and jump risks and also documented that idiosyncratic jumps are important determinants of the mean returns of a stock from both an ex post and ex ante perspective.

Motivated by the above mentioned insights, we propose to price individual equity options in stochastic volatility jump-diffusion models with a market factor structure, which can be seen as a generalized version of Christoffersen et al. (2018). Specifically, in our proposed model, the individual equity prices are driven by the market factor, as well as an idiosyncratic component that also has stochastic volatility and jump. Due to the model belonging to the affine class, we derive the closed-form solutions for the prices of both the market index and individual equity options by utilizing the Fourier inversion. In addition, we provide the empirical results to test the pricing performance of the proposed factor model based on the S\&P 500 index and the stock of Apple Inc. (AAPL) on options. Toward this end, we empirically compare the pricing performance of the proposed model with those of the other three classical two factor stochastic volatility models being taken as benchmark models. Empirical results presented here confirm that the equity option pricing model considering systematic and idiosyncratic volatility and jump risks may offer a good competitor to the models of Bates (2000), Christoffersen et al. (2009), or Christoffersen et al. (2018) for some other option markets.

The remainder of the paper proceeds as follows. In Section 2, we present a novel factor model for equity option valuation and derive the corresponding closed-form solutions. In Section 3 ,

1 In fact, the work of Xiao and Zhou (2018) is a complement to the recent studies that disentangle the four types of risks in equity premiums, such as Bégin et al. (2020), who developed a GARCH-jump model in which an individual firm's systematic and idiosyncratic risk have both a Gaussian diffusive and a jump component. Their empirical results showed that normal diffusive and jump risks have drastically different effects on the expected return of individual stocks by using 20 years of returns and options on the S\&P 500 and 260 stocks. 
empirical studies are carried out to show the pricing performance of our proposed model. Finally, some conclusions are stated in Section 4.

\section{Equity Option Valuation}

In this section, we introduce a general class of stochastic volatility models with jumps for the dynamics of both the market factor and individual equity prices and derive closed form solutions to the prices of the European equity call and put options.

\subsection{Model Description}

Consider a filtered probability space $(\Omega, \mathcal{F}, \mathbb{Q})$ with information filtration $\left\{\mathcal{F}_{t}\right\}_{0 \leq t \leq T}$ satisfying the usual conditions (increase, right-continuous, and augmented), where $\mathbb{Q}$ is a risk neutral measure. We model an equity market consisting of $N$ firms with a single market factor, $I_{t}$ (usually approximated by a market index in practice). The individual stock prices are denoted by $S_{t}^{i}$, for $i=1,2, \ldots, N$. For the sake of convenience, we ignore the superscript $i$, and denote $\left(S_{t}\right)_{t \geq 0}$ the pricing process of an individual stock. Investors also have access to a risk free bond that pays a return rate of $r$. To start, the market factor $I_{t}$ evolves under a risk neutral measure $\mathbb{Q}$ as:

$$
\begin{gathered}
\frac{d I_{t}}{I_{t-}}=r d t+\sqrt{V_{I, t}} d W_{1, t}^{I}+\int_{R}\left(e^{y}-1\right) \tilde{N}_{y}(d t, d y), \\
d V_{I, t}=\kappa_{I}\left(\theta_{I}-V_{I, t}\right) d t+\sigma_{I} \sqrt{V_{I, t}} d W_{2, t}^{I},
\end{gathered}
$$

where $I_{t-}$ stands for the value of $I_{t}$ before a possible jump occurs, $y \in R=\mathbb{R} \backslash\{0\}, V_{I, t}$ is the variance of market factor, $\theta_{I}$ denotes the long run variance, $\kappa_{I}$ captures the mean reversion speed of $V_{I, t}$ to $\theta_{I}, \sigma_{I}$ measures the volatility of volatility, $2 \kappa_{I} \theta_{I} \geq \sigma_{I}^{2}$ to ensure that the process $V_{I, t}$ remains strictly positive $^{2}, W_{1, t}^{I}$ and $W_{2, t}^{I}$ are correlated standard Brownian motions, i.e., the innovations to the market return and volatility are correlated with correlation coefficient $\rho_{I}, \operatorname{Cov}\left(d W_{1, t}^{I}, d W_{2, t}^{I}\right)=\rho_{I} d t$, and $\tilde{N}_{y}(d t, d y)=N_{y}(d t, d y)-v_{y}(d y) d t$ is a compensated jump measure, where $N_{y}(d t, d y)$ is the jump measure and the Lévy kernel (or density) $v_{y}(d y)$ satisfies $\int_{R} \min \left(1, y^{2}\right) v_{y}(d y)<\infty$.

Furthermore, we separate the effects of the market factor on individual equities' returns into two types of risks: the systematic diffusive volatility and jump. More specifically, the diffusive random variation of individual equities' returns is dependent on the Brownian motion that drives market returns through the coefficient $\beta_{\text {diff }}$. In addition, the discontinuous movements in the market return can also trigger jumps in individual equities' returns through the coefficient $\beta_{\text {jump }}$. Therefore, the individual equity prices are driven by the market factor, as well as an idiosyncratic component that also has stochastic volatility and jump, whose process under a risk neutral measure $\mathbb{Q}$ follows: ${ }^{3}$

$$
\begin{gathered}
\frac{d S_{t}}{S_{t-}}=r d t+ \\
+\underbrace{\beta_{d i f f} \sqrt{V_{I, t}} d W_{1, t}^{I}}_{\text {Systematic diffusive }}+\underbrace{\int_{R}\left(e^{\beta_{j u m p} y}-1\right) \tilde{N}_{y}(d t, d y)}_{\text {Systematic jump }}+\underbrace{\sqrt{V_{S, t}} d W_{1, t}^{S}}_{\text {Idiosyncratic diffusive }} \\
+\underbrace{\int_{R}\left(e^{\xi}-1\right) \tilde{N}_{\xi}(d t, d \xi)}_{\text {Idiosyncratic jump }}, \\
d V_{S, t}=\kappa_{S}\left(\theta_{S}-V_{S, t}\right) d t+\sigma_{S} \sqrt{V_{S, t}} d W_{2, t}^{S},
\end{gathered}
$$

\footnotetext{
One can refer to Assumption 2.1 of Cheang et al. (2013) and Cheang and Garces (2019) for a more detailed explanation. Obviously, our proposed model for the dynamics of the market factor and individual equity prices is an extension of Christoffersen et al. (2018). In fact, our model also can be regarded as a further generalization of Cheang et al. (2013) and Cheang and Garces (2019) by taking into account the factor structure.
} 
where $S_{t-}$ stands for the value of $S_{t}$ before a possible jump occurs, $\xi \in R=\mathbb{R} \backslash\{0\}, V_{S, t}$ is the idiosyncratic variance of individual equity, $\theta_{S}$ denotes the long run idiosyncratic variance, $\kappa_{S}$ captures the mean reversion speed of $V_{S, t}$ to $\theta_{S}, \sigma_{S}$ measures the volatility of idiosyncratic variance, $2 \kappa_{S} \theta_{S} \geq \sigma_{S}^{2}$ to ensure that the process $V_{S, t}$ remains strictly positive ${ }^{4}, W_{1, t}^{S}$ and $W_{2, t}^{S}$ are correlated standard Brownian motions, i.e., the innovations to the idiosyncratic return and volatility are correlated with correlation coefficient $\rho_{S}, \operatorname{Cov}\left(d W_{1, t}^{S}, d W_{2, t}^{S}\right)=\rho_{S} d t$, but they are independent of Brownian motions in the market factor, i.e., $\operatorname{Cov}\left(d W_{i, t}^{S}, d W_{j, t}^{I}\right)=0$ for $i, j=1,2$, and $\tilde{N}_{\xi}(d t, d y)=N_{\xi}(d t, d \xi)-v_{\xi}(d \xi) d t$ is a compensated jump measure, where $N_{\xi}(d t, d \xi)$ is the jump measure and the Lévy kernel (or density) $v_{\xi}(d \xi)$ satisfies $\int_{R} \min \left(1, \xi^{2}\right) v_{\xi}(d \xi)<\infty$.

\subsection{Characteristic Function}

In order to be able to derive the pricing formulas for the European call and put equity options, we are particularly interested in the characteristic function of the logarithm asset price. Given the dynamics of the underlying asset price under the $\mathbb{Q}$ measure, we consider the conditional characteristic function of log-asset price $X_{T}=\ln S_{T}$ given the market information up to time $t$, which is denoted by $\varphi\left(x, v_{1}, v_{2}, t, T ; \phi\right)$ :

$$
\begin{aligned}
\varphi\left(x, v_{1}, v_{2}, t, T ; \phi\right) & =\mathrm{E}^{\mathbb{Q}}\left[e^{\mathrm{i} \phi X_{T}} \mid X_{t}=x, V_{I, t}=v_{1}, V_{S, t}=v_{2}\right] \\
& \triangleq \mathrm{E}_{t}^{\mathbb{Q}}\left[e^{\mathrm{i} \phi X_{T}}\right]
\end{aligned}
$$

where $\mathrm{E}_{t}^{\mathbb{Q}}[\cdot]$ denotes the condition expectation under the $\mathbb{Q}$ measure, $t \leq T$, and $\mathrm{i}=\sqrt{-1}$.

Lemma 1. Suppose that the market factor $I_{t}$ and individual equity price $S_{t}$ are driven by Equations (1) and (3), respectively. Then, the conditional characteristic function of $\log$-asset price $X_{T}=\ln S_{T}$ is given by:

$$
\varphi\left(x, v_{1}, v_{2}, t, T ; \phi\right)=\exp \left\{A(\tau) x+B(\tau) v_{1}+C(\tau) v_{2}+D(\tau)\right\},
$$

where:

$$
\begin{aligned}
A(\tau)= & \mathrm{i} \phi, \\
B(\tau)= & \frac{\kappa_{I}-\mathrm{i} \phi \beta_{d i f f} \sigma_{I} \rho_{I}-d_{1}}{\sigma_{I}^{2}}\left[\frac{1-e^{-d_{1} \tau}}{1-g_{1} e^{-d_{1} \tau}}\right], \\
C(\tau)= & \frac{\kappa_{S}-\mathrm{i} \phi \sigma_{S} \rho_{S}-d_{2}}{\sigma_{S}^{2}}\left[\frac{1-e^{-d_{2} \tau}}{1-g_{2} e^{-d_{2} \tau}}\right], \\
D(\tau)= & {[\mathrm{i} \phi r+\underbrace{\int_{R}\left(e^{\mathrm{i} \phi \beta_{j u m p} y}-1-\mathrm{i} \phi\left(e^{\beta_{j u m p} y}-1\right)\right) v_{y}(d y)}_{\mathrm{I}_{1}}+\underbrace{\int_{R}\left(e^{\mathrm{i} \phi \xi}-1-\mathrm{i} \phi\left(e^{\xi}-1\right)\right) v_{\xi}(d \xi)}_{\mathrm{I}_{2}}] \tau } \\
& +\frac{\kappa_{I} \theta_{I}}{\sigma_{I}^{2}}\left[\left(\kappa_{I}-\mathrm{i} \phi \beta_{d i f f} \sigma_{I} \rho_{I}-d_{1}\right) \tau-2 \ln \frac{1-g_{1} e^{-d_{1} \tau}}{1-g_{1}}\right] \\
& +\frac{\kappa_{S} \theta_{S}}{\sigma_{S}^{2}}\left[\left(\kappa_{S}-\mathrm{i} \phi \sigma_{S} \rho_{S}-d_{2}\right) \tau-2 \ln \frac{1-g_{2} e^{-d_{2} \tau}}{1-g_{2}}\right], \\
g_{1}= & \frac{\kappa_{I}-\mathrm{i} \phi \beta_{\text {diff }} \sigma_{I} \rho_{I}-d_{1}}{\kappa_{I}-\mathrm{i} \phi \beta_{\text {diff }} \sigma_{I} \rho_{I}+d_{1}},
\end{aligned}
$$




$$
\begin{aligned}
g_{2} & =\frac{\kappa_{S}-\mathrm{i} \phi \sigma_{S} \rho_{S}-d_{2}}{\kappa_{S}-\mathrm{i} \phi \sigma_{S} \rho_{S}+d_{2}}, \\
d_{1} & =\sqrt{\left(\mathrm{i} \phi \beta_{d i f f} \sigma_{I} \rho_{I}-\kappa_{I}\right)^{2}+\beta_{d i f f}^{2} \sigma_{I}^{2}\left(\mathrm{i} \phi+\phi^{2}\right)}, \\
d_{2} & =\sqrt{\left(\mathrm{i} \phi \sigma_{S} \rho_{S}-\kappa_{S}\right)^{2}+\sigma_{S}^{2}\left(\mathrm{i} \phi+\phi^{2}\right)}, \\
\text { and } \tau & =T-t .
\end{aligned}
$$

Proof. To obtain the conditional characteristic function of log-asset price $X_{T}=\ln S_{T}$, we first take the following transformation by using the Itô lemma for Equation (3):

$$
\begin{aligned}
d \ln S_{t}= & \left(r-\frac{1}{2} \beta_{d i f f}^{2} V_{I, t}-\frac{1}{2} V_{S, t}-\int_{R}\left(e^{\beta_{\text {jump }} y}-1\right) v_{y}(d y)-\int_{R}\left(e^{\xi}-1\right) v_{\xi}(d \xi)\right) d t \\
& +\beta_{\text {diff }} \sqrt{V_{I, t}} d W_{1, t}^{I}+\beta_{j u m p} \int_{R} y N_{y}(d t, d y)+\sqrt{V_{S, t}} d W_{1, t}^{S}+\int_{R} \xi N_{\xi}(d t, d \xi) .
\end{aligned}
$$

The Feynman-Kac formula states that $\varphi\left(x, v_{1}, v_{2}, t, T ; \phi\right)$ is governed by the following partial integro-differential equation (PIDE):

$$
\left\{\begin{aligned}
& \frac{\partial \varphi}{\partial \tau}=[\left.r-\frac{1}{2} \beta_{d i f f}^{2} V_{I, t}-\frac{1}{2} V_{S, t}-\int_{R}\left(e^{\beta_{j u m p} y}-1\right) v_{y}(d y)-\int_{R}\left(e^{\xi}-1\right) v_{\xi}(d \xi)\right] \frac{\partial \varphi}{\partial x} \\
&+\frac{1}{2}\left(\beta_{d i f f}^{2} v_{1}+v_{2}\right) \frac{\partial^{2} \varphi}{\partial x^{2}}+\kappa_{I}\left(\theta_{I}-v_{1}\right) \frac{\partial \varphi}{\partial v_{1}}+\frac{1}{2} \sigma_{I}^{2} v_{1} \frac{\partial^{2} \varphi}{\partial v_{1}^{2}} \\
&+\kappa_{S}\left(\theta_{S}-v_{2}\right) \frac{\partial \varphi}{\partial v_{2}}+\frac{1}{2} \sigma_{S}^{2} v_{2} \frac{\partial^{2} \varphi}{\partial v_{2}^{2}}+\beta_{d i f f} \sigma_{I} \rho_{I} v_{1} \frac{\partial^{2} \varphi}{\partial x \partial v_{1}}+\sigma_{S} \rho_{S} v_{2} \frac{\partial^{2} \varphi}{\partial x \partial v_{2}} \\
&+\int_{R}\left[\varphi\left(x+\beta_{j u m p} y, v_{1}, v_{2}, t, T ; \phi\right)-\varphi\left(x, v_{1}, v_{2}, t, T ; \phi\right)\right] v_{y}(d y) \\
&+\int_{R}\left[\varphi\left(x+\xi, v_{1}, v_{2}, t, T ; \phi\right)-\varphi\left(x, v_{1}, v_{2}, t, T ; \phi\right)\right] v_{\xi}(d \xi) \\
&\left.\varphi\left(x, v_{1}, v_{2}, t, T ; \phi\right)\right|_{t=T}=e^{\mathrm{i} \phi X_{T}} .
\end{aligned}\right.
$$

Due to the affine structure of our model, we postulate $\varphi\left(x, v_{1}, v_{2}, t, T ; \phi\right)$ admitting the form of (6). Substituting Equation (6) into the above PIDE (7) gives the following system of ordinary differential equations (ODEs) for $A(\tau), B(\tau), C(\tau)$, and $D(\tau)$ :

$$
\left\{\begin{aligned}
& \frac{\partial A(\tau)}{\partial \tau}=0 \\
& \frac{\partial B(\tau)}{\partial \tau}= \frac{1}{2} \sigma_{I}^{2} B^{2}(\tau)+\left[\beta_{\text {diff }} \sigma_{I} \rho_{I} A(\tau)-\kappa_{I}\right] B(\tau)-\frac{1}{2} \beta_{\text {diff }}^{2}\left[A(\tau)-A^{2}(\tau)\right] \\
& \frac{\partial C(\tau)}{\partial \tau}= \frac{1}{2} \sigma_{S}^{2} C^{2}(\tau)+\left[\sigma_{S} \rho_{S} A(\tau)-\kappa_{S}\right] C(\tau)-\frac{1}{2}\left[A(\tau)-A^{2}(\tau)\right] \\
& \frac{\partial D(\tau)}{\partial \tau}= r A(\tau)+\kappa_{I} \theta_{I} B(\tau)+\kappa_{S} \theta_{S} C(\tau)+\int_{R}\left[e^{A(\tau) \beta_{j u m p} y}-1-A(\tau)\left(e^{\beta_{\text {jump }} y}-1\right)\right] v_{y}(d y) \\
& \quad+\int_{R}\left[e^{A(\tau) \xi}-1-A(\tau)\left(e^{\xi}-1\right)\right] v_{\xi}(d \xi)
\end{aligned}\right.
$$

where the boundary conditions are given as $A(0)=\mathrm{i} \phi$ and $B(0)=C(0)=D(0)=0$.

By solving the above ODEs, we can obtain the characteristic function (6). 
Lemma 2. Suppose that the market factor $I_{t}$ is driven by Equation (1). Then, the conditional characteristic function of log-market factor $Z_{T}=\ln I_{T}$ is given by:

$$
\begin{aligned}
\psi\left(z, v_{1}, t, T ; \phi\right) & =\mathrm{E}^{\mathbb{Q}}\left[e^{\mathrm{i} \phi Z_{T}} \mid Z_{t}=z, V_{I, t}=v_{1}\right] \\
& =\exp \left\{\tilde{A}(\tau) z+\tilde{B}(\tau) v_{1}+\tilde{D}(\tau)\right\}
\end{aligned}
$$

where:

$$
\begin{aligned}
& \tilde{A}(\tau)=\mathrm{i} \phi \\
& \tilde{B}(\tau)=\frac{\kappa_{I}-\mathrm{i} \phi \sigma_{I} \rho_{I}-d}{\sigma_{I}^{2}}\left[\frac{1-e^{-d \tau}}{1-g e^{-d \tau}}\right] \\
& \tilde{D}(\tau)=[\mathrm{i} \phi r+\underbrace{\int_{R}\left(e^{\mathrm{i} \phi y}-1-\mathrm{i} \phi\left(e^{y}-1\right)\right) v_{y}(d y)}_{\mathrm{I}_{3}}] \tau+\frac{\kappa_{I} \theta_{I}}{\sigma_{I}^{2}}\left[\left(\kappa_{I}-\mathrm{i} \phi \sigma_{I} \rho_{I}-d\right) \tau-2 \ln \frac{1-g e^{-d \tau}}{1-g}\right], \\
& g=\frac{\kappa_{I}-\mathrm{i} \phi \sigma_{I} \rho_{I}-d}{\kappa_{I}-\mathrm{i} \phi \sigma_{I} \rho_{I}+d^{\prime}} \\
& d=\sqrt{\left(\mathrm{i} \phi \sigma_{I} \rho_{I}-\kappa_{I}\right)^{2}+\sigma_{I}^{2}\left(\mathrm{i} \phi+\phi^{2}\right)} \\
& \text { and } \tau=T-t .
\end{aligned}
$$

Proof. Similar to the proof of Lemma 1, we can easily verify the above results.

\subsection{Valuation of the European Index and Equity Options}

Once the characteristic function is found, it is straightforward to calculate the prices of European options by using Fourier inversion. Let $C\left(S_{t}, T, K\right)$ and $P\left(S_{t}, T, K\right)$ be the prices of the European equity call and put options at time $t$ with strike price $K$ and maturity $T$ under the risk neutral measure $\mathbb{Q}$, respectively. Then, these option prices are determined by:

$$
C\left(S_{t}, T, K\right)=e^{-r \tau} \mathrm{E}_{t}^{\mathbb{Q}}\left[\max \left(S_{T}-K, 0\right)\right]
$$

and:

$$
P\left(S_{t}, T, K\right)=e^{-r \tau} \mathrm{E}_{t}^{\mathbb{Q}}\left[\max \left(K-S_{T}, 0\right)\right]
$$

where $\tau=T-t$ is the time to maturity.

Theorem 1. Suppose that the market factor $I_{t}$ and the individual equity price $S_{t}$ are driven by Equations (1) and (3), respectively. Then, the prices of the European equity call and put options with strike price $K$ and maturity $\tau=T-$ t are given by:

$$
C\left(S_{t}, T, K\right)=S_{t} \Pi_{1}\left(S_{t}, T, K ; \beta_{\text {diff }}, \beta_{j u m p}\right)-K e^{-r \tau} \Pi_{2}\left(S_{t}, T, K ; \beta_{\text {diff }}, \beta_{j u m p}\right)
$$

and:

$$
P\left(S_{t}, T, K\right)=K e^{-r \tau}\left[1-\Pi_{2}\left(S_{t}, T, K ; \beta_{\text {diff }}, \beta_{j u m p}\right)\right]-S_{t}\left[1-\Pi_{1}\left(S_{t}, T, K ; \beta_{\text {diff }}, \beta_{j u m p}\right)\right]
$$

where the risk neutral probability distribution functions $\Pi_{1}$ and $\Pi_{2}$ are defined by:

$$
\Pi_{1}\left(S_{t}, T, K ; \beta_{\text {diff }}, \beta_{\text {jump }}\right)=\frac{1}{2}+\frac{e^{-r \tau}}{\pi S_{t}} \int_{0}^{+\infty} \Re\left[\frac{e^{-\mathrm{i} \phi \ln K} \varphi\left(x, v_{1}, v_{2}, t, T ; \phi-\mathrm{i}\right)}{\mathrm{i} \phi}\right] d \phi
$$


and:

$$
\Pi_{2}\left(S_{t}, T, K ; \beta_{\text {diff }}, \beta_{j u m p}\right)=\frac{1}{2}+\frac{1}{\pi} \int_{0}^{+\infty} \Re\left[\frac{e^{-\mathrm{i} \phi \ln K} \varphi\left(x, v_{1}, v_{2}, t, T ; \phi\right)}{\mathrm{i} \phi}\right] d \phi,
$$

where $\varphi\left(x, v_{1}, v_{2}, t, T ; \phi\right)$ is the conditional characteristic function of $\ln S_{T}$, which can be seen in Equation (6), and $\Re[\cdot]$ indicates the real part of a complex number.

Proof. In order to get the pricing formulas of the European equity call and put options, let us first introduce a change of measure from $\mathbb{Q}$ to $\tilde{\mathbb{Q}}$ by the following Radon-Nikodym derivative:

$$
\frac{d \tilde{\mathbb{Q}}}{d \mathbb{Q}}=e^{-r(T-t)} \frac{S_{T}}{S_{t}} .
$$

We denote the conditional characteristic function of $X_{T}=\ln S_{T}$ under the $\tilde{\mathbb{Q}}$ measure by $\tilde{\varphi}\left(x, v_{1}, v_{2}, t, T ; \phi\right)$. Then, $\tilde{\varphi}\left(x, v_{1}, v_{2}, t, T ; \phi\right)$ can be expressed as:

$$
\begin{aligned}
\tilde{\varphi}\left(x, v_{1}, v_{2}, t, T ; \phi\right) & =\mathrm{E}_{t}^{\tilde{\mathbb{Q}}}\left[e^{\mathrm{i} \phi X_{T}}\right] \\
& =\mathrm{E}_{t}^{\mathbb{Q}}\left[e^{-r(T-t)} \frac{S_{T}}{S_{t}} e^{\mathrm{i} \phi X_{T}}\right] \\
& =e^{-r(T-t)-x} \mathrm{E}_{t}^{\mathbb{Q}}\left[e^{\mathrm{i}(\phi-\mathrm{i}) X_{T}}\right] \\
& =e^{-r(T-t)-x} \varphi\left(x, v_{1}, v_{2}, t, T ; \phi-\mathrm{i}\right) .
\end{aligned}
$$

Thus, the price of a European equity call option $C\left(S_{t}, T, K\right)$ can be calculated by utilizing $\varphi\left(x, v_{1}, v_{2}, t, T ; \phi\right)$ and $\tilde{\varphi}\left(x, v_{1}, v_{2}, t, T ; \phi\right)$ :

$$
\begin{aligned}
C\left(S_{t}, T, K\right) & =e^{-r \tau} \mathrm{E}_{t}^{\mathbb{Q}}\left[\max \left(S_{T}-K, 0\right)\right] \\
& =e^{-r \tau} \mathrm{E}_{t}^{\mathbb{Q}}\left[S_{T} 1_{\left\{S_{T} \geq K\right\}}\right]-K e^{-r \tau} \mathrm{E}_{t}^{\mathbb{Q}}\left[1_{\left\{S_{T} \geq K\right\}}\right] \\
& =S_{t} \mathrm{E}_{t}^{\tilde{\mathbb{Q}}}\left[1_{\left\{S_{T} \geq K\right\}}\right]-K e^{-r \tau} \mathrm{E}_{t}^{\mathbb{Q}}\left[1_{\left\{S_{T} \geq K\right\}}\right] \\
& =S_{t} \mathrm{E}_{t}^{\tilde{Q}}\left[1_{\left\{X_{T} \geq \ln K\right\}}\right]-K e^{-r \tau} \mathrm{E}_{t}^{\mathbb{Q}}\left[1_{\left\{X_{T} \geq \ln K\right\}}\right] \\
& =S_{t} \Pi_{1}\left(S_{t}, T, K ; \beta_{\text {diff }}, \beta_{j u m p}\right)-K e^{-r \tau} \Pi_{2}\left(S_{t}, T, K ; \beta_{\text {diff }}, \beta_{j u m p}\right) .
\end{aligned}
$$

Once the conditional characteristic function $\varphi\left(x, v_{1}, v_{2}, t, T ; \phi\right)$ is obtained, we can easily calculate the probability distribution functions $\Pi_{1}\left(S_{t}, T, K ; \beta_{\text {diff }}, \beta_{j u m p}\right)$ and $\Pi_{2}\left(S_{t}, T, K ; \beta_{\text {diff }}, \beta_{j u m p}\right)$ according to the Lévy inversion formula:

$$
\Pi_{1}\left(S_{t}, T, K ; \beta_{\text {diff }}, \beta_{j u m p}\right)=\frac{1}{2}+\frac{1}{\pi} \int_{0}^{+\infty} \Re\left[\frac{e^{-\mathrm{i} \phi \ln K} \tilde{\varphi}\left(x, v_{1}, v_{2}, t, T ; \phi\right)}{\mathrm{i} \phi}\right] d \phi
$$

and:

$$
\Pi_{2}\left(S_{t}, T, K ; \beta_{\text {diff }}, \beta_{j u m p}\right)=\frac{1}{2}+\frac{1}{\pi} \int_{0}^{+\infty} \Re\left[\frac{e^{-\mathrm{i} \phi \ln K} \varphi\left(x, v_{1}, v_{2}, t, T ; \phi\right)}{\mathrm{i} \phi}\right] d \phi,
$$

A similar approach can be used to derive the pricing formula for the European equity put option.

In a similar way, we also can present the pricing formulas for the European index call and put options. 
Theorem 2. Suppose that the market factor $I_{t}$ is driven by Equation (1). Then, the time t prices of the European index call and put options with strike price $K$ and maturity $\tau=T-t$ are given by:

$$
C\left(I_{t}, T, K\right)=I_{t} \tilde{\Pi}_{1}\left(I_{t}, T, K\right)-K e^{-r \tau} \tilde{\Pi}_{2}\left(I_{t}, T, K\right)
$$

and:

$$
P\left(I_{t}, T, K\right)=K e^{-r \tau}\left[1-\tilde{\Pi}_{2}\left(I_{t}, T, K\right)\right]-I_{t}\left[1-\tilde{\Pi}_{1}\left(I_{t}, T, K\right)\right]
$$

where the risk neutral probability distribution functions $\Pi_{1}$ and $\Pi_{2}$ are defined by:

$$
\tilde{\Pi}_{1}\left(I_{t}, T, K\right)=\frac{1}{2}+\frac{e^{-r \tau}}{\pi I_{t}} \int_{0}^{+\infty} \Re\left[\frac{e^{-\mathrm{i} \phi \ln K} \psi\left(z, v_{1}, t, T ; \phi-\mathrm{i}\right)}{\mathrm{i} \phi}\right] d \phi
$$

and:

$$
\tilde{\Pi}_{2}\left(I_{t}, T, K\right)=\frac{1}{2}+\frac{1}{\pi} \int_{0}^{+\infty} \Re\left[\frac{e^{-\mathrm{i} \phi \ln K} \psi\left(z, v_{1}, t, T ; \phi\right)}{\mathrm{i} \phi}\right] d \phi,
$$

where $\psi\left(z, v_{1}, t, T ; \phi\right)$ is the conditional characteristic function of $\ln I_{T}$, which can be seen in Equation (8).

\section{Empirical Studies}

In this section, we empirically compare the pricing performance of our proposed model with those of the classical two factor stochastic volatility models, such as Bates (2000) (two variance SVmodel with price jumps, 2-SVJmodel), Christoffersen et al. (2009) (two-variance SV model, 2-SV model), and Christoffersen et al. (2018) (two-variance SV model with a single market factor, 2-FSVmodel), being taken as benchmark models.

\subsection{Data Description}

We used the S\&P 500 index (SPX) to proxy for the market factor and AAPL as the individual equity. We employed the delayed market quotes on arbitrary date 8 May 2019, which was the last date available at the time of writing, as the in-sample data to calibrate the risk neutral parameters, and those on 9 May 2019 were used for the out-of-sample test. We used mid-quotes to represent the option prices. To eliminate the sample noise in raw option data, we adopted some filtering rules commonly used within the related literature: (i) we omitted those options with fewer than seven days and more than 365 days to maturity; (ii) all observations with zero trading volume were discarded; (iii) all options with implied volatility equal to zero and larger than 1.0 were discarded. In addition, for the convenience of the empirical analysis in the following, we only considered the sample data of the index call options and individual equity call options with the same expiration date. Thus, we focused only on ten maturities slices, namely on the maturities of 24 May 2019, 31 May 2019, 7 June 2019, 14 June 2019, 21 June 2019, 19 July 2019, 16 August 2019, 20 September 2019, 18 October 2019, and 17 January 2020.

After these filters, we had a total of 401 observations for the S\&P 500 index call option on 8 May 2019. The individual equity option sample contained 233 call options on 8 May 2019 and 264 call options on 9 May 2019, respectively. Due to the life of an option being usually less than one year, we chose the three month U.S. Treasury Bill Rate to substitute for the risk free interest rate. All of the data were downloaded from the Chicago Board Options Exchange (http:/ /www.cboe.com/).

\subsection{Parameter Estimation}

Our proposed model allowed a general distribution for jump components of the market factor and individual equity price and thus could be easily introduced to the special cases such that the jump components follow the compound Poisson process of Merton (1976) and Kou (2002), etc. For different types of Lévy kernels, different forms of our model can be presented. In order to keep consistent with 
Bates (2000) for comparative analysis, in the following, we assumed that the jump components of the dynamics for the market factor and individual equity followed compound Poisson processes and the jump magnitude was drawn from the log-normal distribution of Merton (1976). Thus, the Lévy kernels for the market factor and individual equity, respectively, are given by:

$$
v_{y}(d y)=\lambda_{I} \frac{1}{\sqrt{2 \pi \delta_{I}^{2}}} \exp \left\{-\frac{\left(y-\mu_{I}\right)^{2}}{2 \delta_{I}^{2}}\right\} d y
$$

and:

$$
v_{\xi}(d \xi)=\lambda_{S} \frac{1}{\sqrt{2 \pi \delta_{S}^{2}}} \exp \left\{-\frac{\left(\xi-\mu_{S}\right)^{2}}{2 \delta_{S}^{2}}\right\} d \xi,
$$

where $\lambda_{j}$, for $j=I, S$, denotes the jump intensity, $\mu_{j}$ is the mean of the jump size, and $\delta_{j}$ is the variance of the jump size. Then, the integrals $\mathrm{I}_{i}$, for $i=1,2,3$, in Lemmas 1 and 2 can be calculated as follows:

$$
\begin{aligned}
& \mathrm{I}_{1}=\lambda_{I}\left[e^{\mathrm{i} \phi \beta_{j u m p} \mu_{I}-\frac{1}{2} \phi^{2} \beta_{j u m p}^{2} \delta_{I}^{2}}-1-\mathrm{i} \phi\left(e^{\beta_{j u m p} \mu_{I}+\frac{1}{2} \beta_{j u m p}^{2} \delta_{I}^{2}}-1\right)\right], \\
& \mathrm{I}_{2}=\lambda_{S}\left[e^{\mathrm{i} \phi \mu_{S}-\frac{1}{2} \phi^{2} \delta_{S}^{2}}-1-\mathrm{i} \phi\left(e^{\mu_{S}+\frac{1}{2} \delta_{S}^{2}}-1\right)\right],
\end{aligned}
$$

and

$$
\mathrm{I}_{3}=\lambda_{I}\left[e^{\mathrm{i} \phi \mu_{I}-\frac{1}{2} \phi^{2} \delta_{I}^{2}}-1-\mathrm{i} \phi\left(e^{\mu_{I}+\frac{1}{2} \delta_{I}^{2}}-1\right)\right]
$$

Based on Theorems 1 and 2, we employed a two step calibration procedure (see, for example, Wong et al. 2012; Christoffersen et al. 2018) to estimate the model parameters. First, we calibrated the market index dynamic $\Theta_{I}$ based on the S\&P 500 index option price alone. Second, we used the equity option price to calibrate the individual equity dynamic $\Theta_{S}$ conditional on estimates of $\Theta_{I}$. Consider the situation in which an investor wants to hedge his or her equity position with index options and hedging horizon $T$. For brevity, we further suppose that the investor observes index option prices and equity option prices both with maturity $T$, the same as hedging horizon. Specifically, the dataset contains $M_{t}$ index option prices $C\left(I_{t}, T, K_{i}\right)$, for $i=1,2, \ldots, M_{t}$, and $N_{t}$ equity option prices $C\left(S_{t}, T, K_{j}\right)$, for $j=1,2, \ldots, N_{t}$.

In the calibration process, the risk neutral model parameters were backed out by minimizing a loss function capturing the fit between the theoretical model and market prices. We employed the root mean squared errors (RMSE) as the objective function. The first step calibrated the risk neutral parameters for the index process, which are calibrated by:

$$
\operatorname{RMSE}(I)=\arg \min _{\Theta_{I}} \sqrt{\frac{1}{M_{t}} \sum_{i=1}^{M_{t}}\left[C_{i, \text { market }}\left(I_{t}, T, K_{i}\right)-C_{i, \text { model }}^{\Theta_{I}}\left(I_{t}, T, K_{i}\right)\right]^{2}}
$$

where $C_{i, \text { market }}\left(I_{t}, T, K_{i}\right)$ is the market price of the index call option contract from the sample and $C_{i, \text { model }}^{\Theta_{I}}\left(I_{t}, T, K_{i}\right)$ represents the model price calculated using Equation (15) and the vector of model input parameters $\Theta_{I}$.

The second calibrated the beta and the parameters for the idiosyncratic risk:

$$
\operatorname{RMSE}(S)=\arg \min _{\Theta_{S}} \sqrt{\frac{1}{N_{t}} \sum_{j=1}^{N_{t}}\left[C_{j, \text { market }}\left(S_{t}, T, K_{j}\right)-C_{j, \text { model }}^{\Theta_{S}}\left(S_{t}, T, K_{j}\right)\right]^{2}},
$$


where $C_{j, \text { market }}\left(S_{t}, T, K_{j}\right)$ is the market price of the equity call option contract from the sample and $C_{j, \text { model }}^{\Theta_{S}}\left(S_{t}, T, K_{j}\right)$ represents the model price calculated using Equation (13) and the vector of model input parameters $\Theta_{S}$.

On the basis of the above calibration method, Table 1 presents the risk neutral parameter estimates across various model specifications. Note that the values of the diffusive beta $\beta_{\text {diff }}$ and jump beta $\beta_{j u m p}$ for our proposed model were 0.3891 and 0.8429 , respectively. The corresponding value of $\beta_{\text {diff }}$ for the 2-FSV model was 0.2457 . Obviously, both our proposed model and the 2-FSV model showed that AAPL tended to have a relatively low exposure to diffusive market movements. However, the jump exposure coefficient $\beta_{\text {jump }}=0.8429$ indicated that the AAPL had a strong exposure to market jumps, which meant that the factor structure of the jumps was much stronger than the one of the diffusive movements. The reason for this result may be related to the sample data we selected. If we can get more sample data in the future, we will do an in-depth analysis. Moreover, we also can see that the values of correlation $\rho$ were strongly negative for four models, capturing the so-called leverage effect both in the index and individual equity.

Table 1. Estimated parameters. Note: This table shows the average of the estimated parameters obtained by minimizing the root mean squared pricing errors between the market price and the model price for each option on 8 May 2019. Standard errors are reported in parentheses .

\begin{tabular}{|c|c|c|c|c|c|c|}
\hline \multirow{2}{*}{ Parameters } & \multicolumn{2}{|c|}{ Our } & \multicolumn{2}{|c|}{ 2-FSV } & \multirow{2}{*}{$\frac{2-S V}{\text { AAPL }}$} & \multirow{2}{*}{$\frac{2-S V J}{\text { AAPL }}$} \\
\hline & SPX & AAPL & SPX & AAPL & & \\
\hline$V_{I, 0} / V_{1,0}$ & $\begin{array}{c}0.0133 \\
(0.0000)\end{array}$ & & $\begin{array}{c}0.0119 \\
(0.0000)\end{array}$ & & $\begin{array}{c}0.0239 \\
(0.0002)\end{array}$ & $\begin{array}{c}0.0181 \\
(0.0001)\end{array}$ \\
\hline$V_{S, 0} / V_{2,0}$ & & $\begin{array}{c}0.0470 \\
(0.0000)\end{array}$ & & $\begin{array}{c}0.0514 \\
(0.0000)\end{array}$ & $\begin{array}{c}0.0197 \\
(0.0002)\end{array}$ & $\begin{array}{c}0.0176 \\
(0.0002)\end{array}$ \\
\hline$\kappa_{I} / \kappa_{1}$ & $\begin{array}{c}0.2496 \\
(0.0212)\end{array}$ & & $\begin{array}{c}0.2929 \\
(0.0148)\end{array}$ & & $\begin{array}{c}0.3489 \\
(0.0118)\end{array}$ & $\begin{array}{c}0.4064 \\
(0.0311)\end{array}$ \\
\hline$\kappa_{S} / \kappa_{2}$ & & $\begin{array}{c}0.2454 \\
(0.0288)\end{array}$ & & $\begin{array}{c}0.1504 \\
(0.0797)\end{array}$ & $\begin{array}{c}0.4131 \\
(0.0729)\end{array}$ & $\begin{array}{c}0.4108 \\
(0.0171)\end{array}$ \\
\hline$\theta_{I} / \theta_{1}$ & $\begin{array}{c}0.2820 \\
(0.0181)\end{array}$ & & $\begin{array}{c}0.3066 \\
(0.0317)\end{array}$ & & $\begin{array}{c}0.3314 \\
(0.0534)\end{array}$ & $\begin{array}{c}0.2817 \\
(0.0348)\end{array}$ \\
\hline$\theta_{S} / \theta_{2}$ & & $\begin{array}{c}0.2303 \\
(0.0190)\end{array}$ & & $\begin{array}{c}0.3683 \\
(0.0590)\end{array}$ & $\begin{array}{c}0.2447 \\
(0.0365)\end{array}$ & $\begin{array}{c}0.3415 \\
(0.0423)\end{array}$ \\
\hline$\sigma_{I} / \sigma_{1}$ & $\begin{array}{c}0.3472 \\
(0.0127)\end{array}$ & & $\begin{array}{c}0.3932 \\
(0.0137)\end{array}$ & & $\begin{array}{c}0.1615 \\
(0.0081)\end{array}$ & $\begin{array}{c}0.1898 \\
(0.0106)\end{array}$ \\
\hline$\sigma_{S} / \sigma_{2}$ & & $\begin{array}{c}0.1496 \\
(0.0056)\end{array}$ & & $\begin{array}{c}0.1640 \\
(0.0135)\end{array}$ & $\begin{array}{c}0.2206 \\
(0.0386)\end{array}$ & $\begin{array}{c}0.1970 \\
(0.0059)\end{array}$ \\
\hline$\lambda_{I}$ & $\begin{array}{c}0.0450 \\
(0.0017)\end{array}$ & & & & & \\
\hline$\lambda_{S}$ & & $\begin{array}{c}0.3413 \\
(0.2463)\end{array}$ & & & & $\begin{array}{c}0.3065 \\
(0.1194)\end{array}$ \\
\hline$\mu_{I}$ & $\begin{array}{c}0.1657 \\
(0.0599)\end{array}$ & & & & & \\
\hline$\mu_{S}$ & & $\begin{array}{c}0.0889 \\
(0.0391)\end{array}$ & & & & $\begin{array}{c}0.0333 \\
(0.0042)\end{array}$ \\
\hline$\delta_{I}$ & $\begin{array}{c}0.0850 \\
(0.0113)\end{array}$ & & & & & \\
\hline$\delta_{S}$ & & $\begin{array}{c}0.0679 \\
(0.0078)\end{array}$ & & & & $\begin{array}{c}0.0534 \\
(0.0013)\end{array}$ \\
\hline$\beta_{\text {diff }}$ & & $\begin{array}{c}0.3891 \\
(0.0381)\end{array}$ & & $\begin{array}{c}0.2457 \\
(0.0983)\end{array}$ & & \\
\hline$\beta_{j u m p}$ & & $\begin{array}{c}0.8429 \\
(0.8091)\end{array}$ & & & & \\
\hline$\rho_{I} / \rho_{1}$ & $\begin{array}{c}-0.9290 \\
(0.0063)\end{array}$ & & $\begin{array}{c}-0.8498 \\
(0.0080)\end{array}$ & & $\begin{array}{l}-0.9222 \\
(0.0096)\end{array}$ & $\begin{array}{l}-0.7445 \\
(0.0297)\end{array}$ \\
\hline$\rho_{S} / \rho_{2}$ & & $\begin{array}{l}-0.9926 \\
(0.0001)\end{array}$ & & $\begin{array}{l}-0.8938 \\
(0.0469)\end{array}$ & $\begin{array}{c}-0.7673 \\
(0.1632)\end{array}$ & $\begin{array}{l}-0.7817 \\
(0.0549)\end{array}$ \\
\hline
\end{tabular}




\subsection{Pricing Performance}

In this subsection, we present the empirical results for the calibrated models. In order to investigate the impacts of the systematic and idiosyncratic volatility and jump risks on equity option pricing, we took the 2-FSV, 2-SV, and 2-SVJ models as benchmark models to evaluate the pricing performance of our proposed model.

Figures 1-10 exhibit the predicted prices of the four model specifications and market prices listed on 9 May 2019, with 11, 16, 21, 26, 31, 51, 71, 96, 116, and 181 trading days to expiry, respectively. Here, the predicted prices (out-of-sample pricing) were calculated by the in-sample calibration parameters reported in Table 1. One can clearly observe from the left panels of Figures 1-10 that the option prices obtained by theoretical models were generally closer to the market prices for different strike prices. To further investigate the pricing performance of the four models, the right panels of Figures 1-10 show the relative price differences (relative errors) between the theoretical model prices and market prices. ${ }^{5}$ For simplicity, we refer to a call option as deep out-of-the-money (DOTM) if $S / K \leq 0.90$; out-of-the-money (OTM) if $0.90<S / K \leq 0.97$; at-the-money (ATM) if $0.97<S / K \leq 1.03$; in-the-money (ITM) if $0.97<S / K \leq 1.10$; and deep in-the-money (ITM) if $1.10<S / K$. Moreover, we considered options less than 60 days to expiration as short term; options with 60-120 days to expiration as medium term; and options larger than 120 days to expiration as long term. For the options with $11,16,21,26,31$, and 51 trading days to expiry, the relative pricing errors produced by our proposed model were all significantly lower than those of 2-FSV, 2-SV, and 2-SVJ models in the case of DOTM options, while the relative errors of all models were slightly higher.

It is also worth noting that the pricing performance of the stochastic model with jump behavior was much better than that of the model without jump in the case of deep out-of-money. For the options with $71,96,116$, and 181 trading days to expiry, we did not find the same conclusions as the above short term options. In conclusion, the pricing performance of equity option valuation model considering market and idiosyncratic volatility and jump risks was significantly improved for short term and DOTM options.
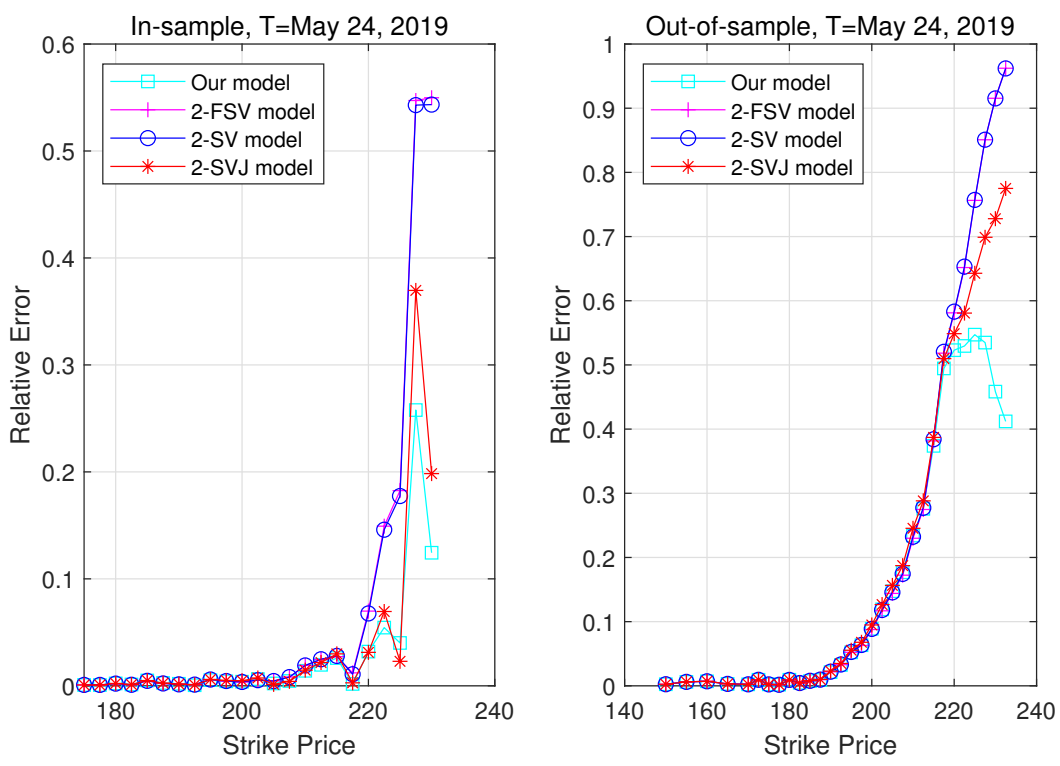

Figure 1. The comparison of predicted prices of four model specifications and market prices on 9 May 2019, with maturity $T=24$ May 2019.

5 The relative error is defined by $\frac{\left|C_{\text {model }}-C_{\text {market }}\right|}{C_{\text {market }}} \times 100 \%$, where $C_{\text {model }}$ and $C_{\text {market }}$ denote the theoretical model option prices and the real market prices, respectively. 

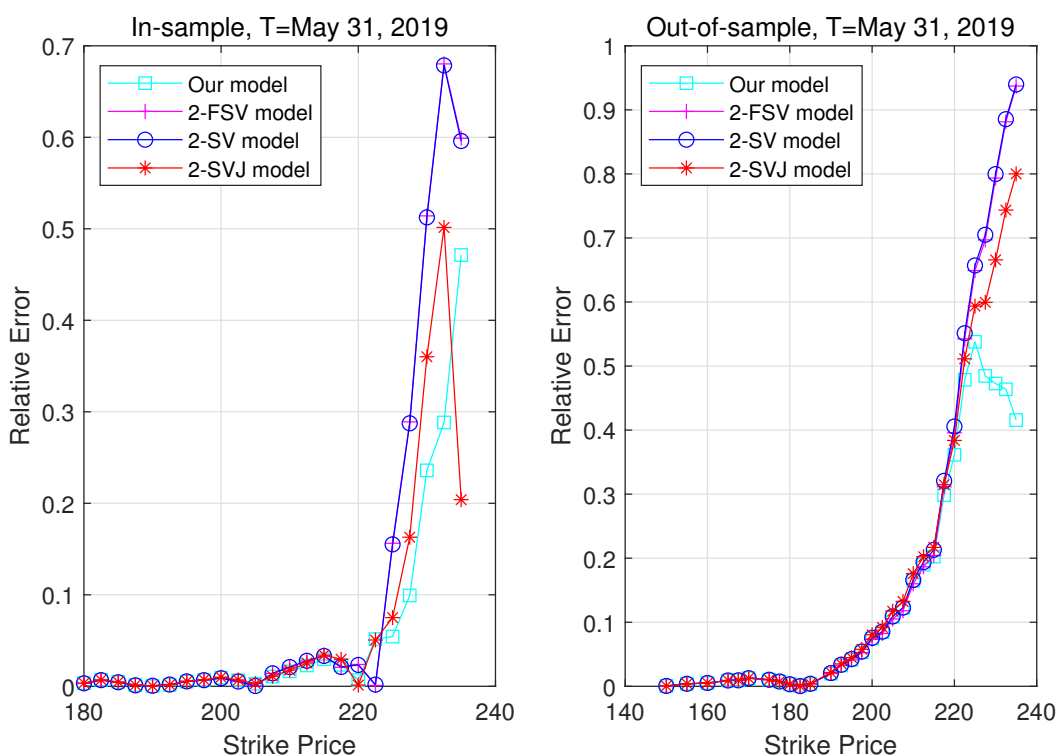

Figure 2. The comparison of predicted prices of four model specifications and market prices on 9 May 2019, with maturity $T=31$ May 2019.
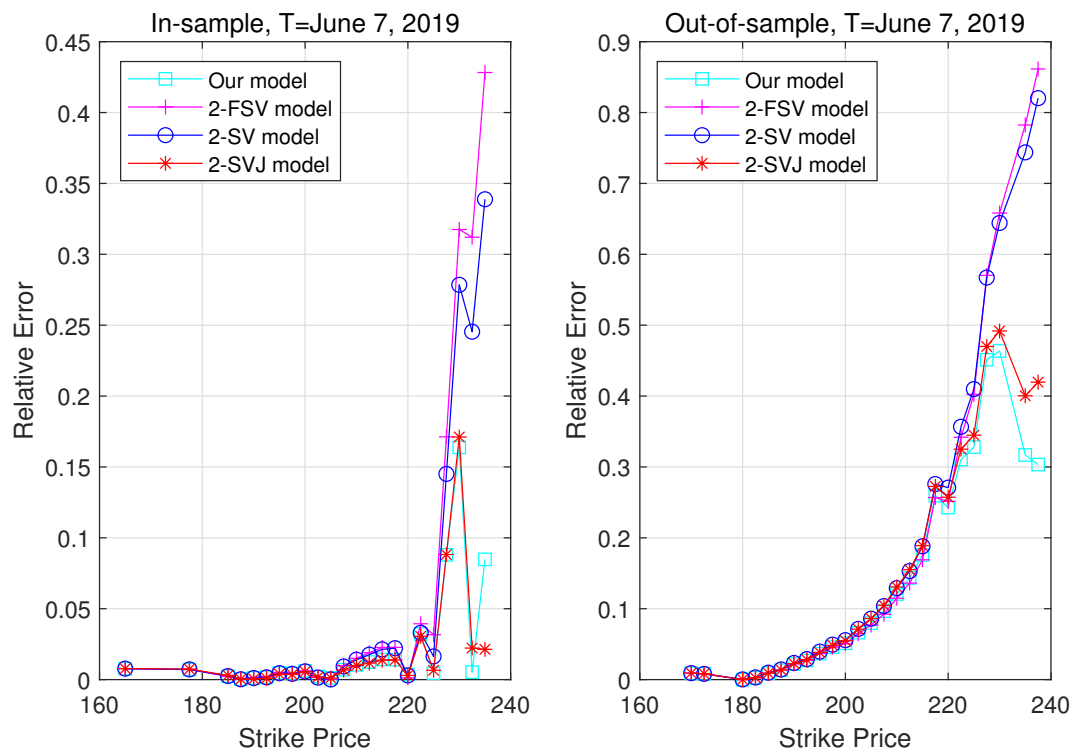

Figure 3. The comparison of predicted prices of four model specifications and market prices on 9 May 2019, with maturity $T=7$ June 2019. 

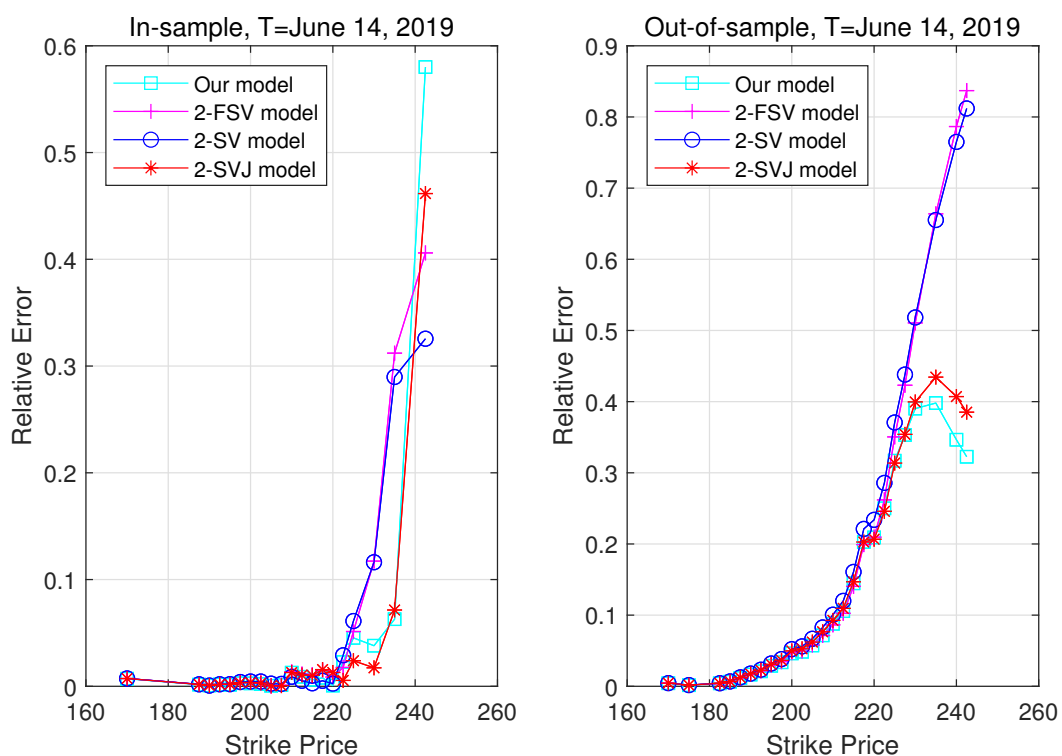

Figure 4. The comparison of predicted prices of four model specifications and market prices on 9 May 2019, with maturity $T=14$ June 2019.
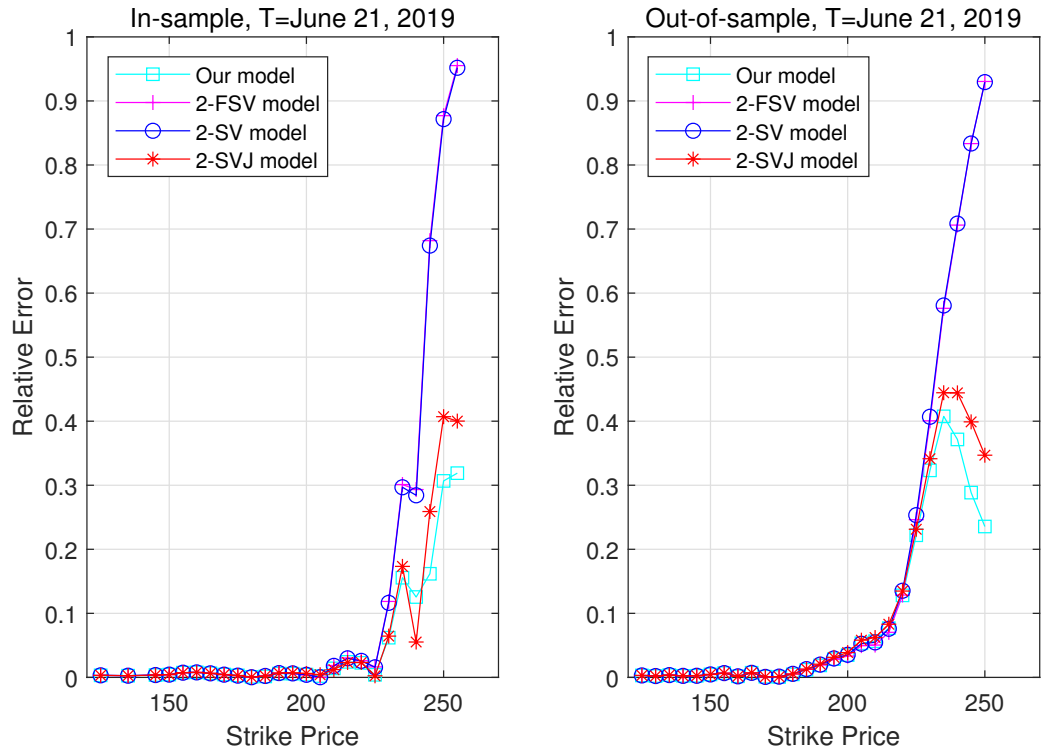

Figure 5. The comparison of predicted prices of four model specifications and market prices on 9 May 2019, with maturity $T=21$ June 2019. 

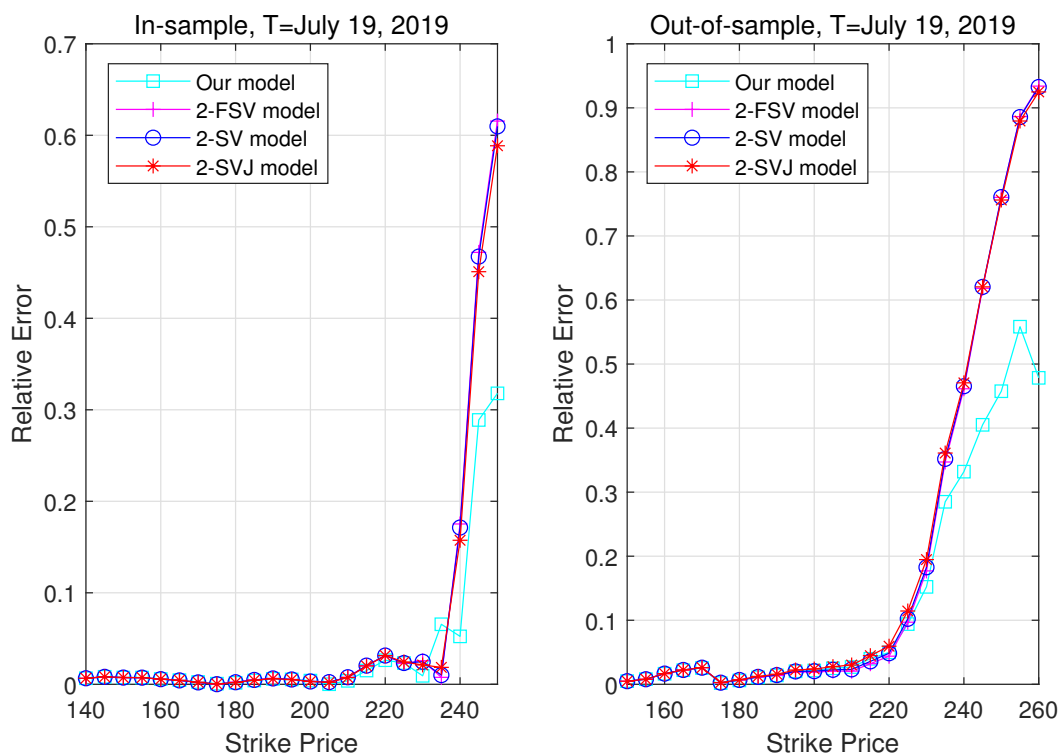

Figure 6. The comparison of predicted prices of four model specifications and market prices on 9 May 2019, with maturity $T=19$ July 2019.
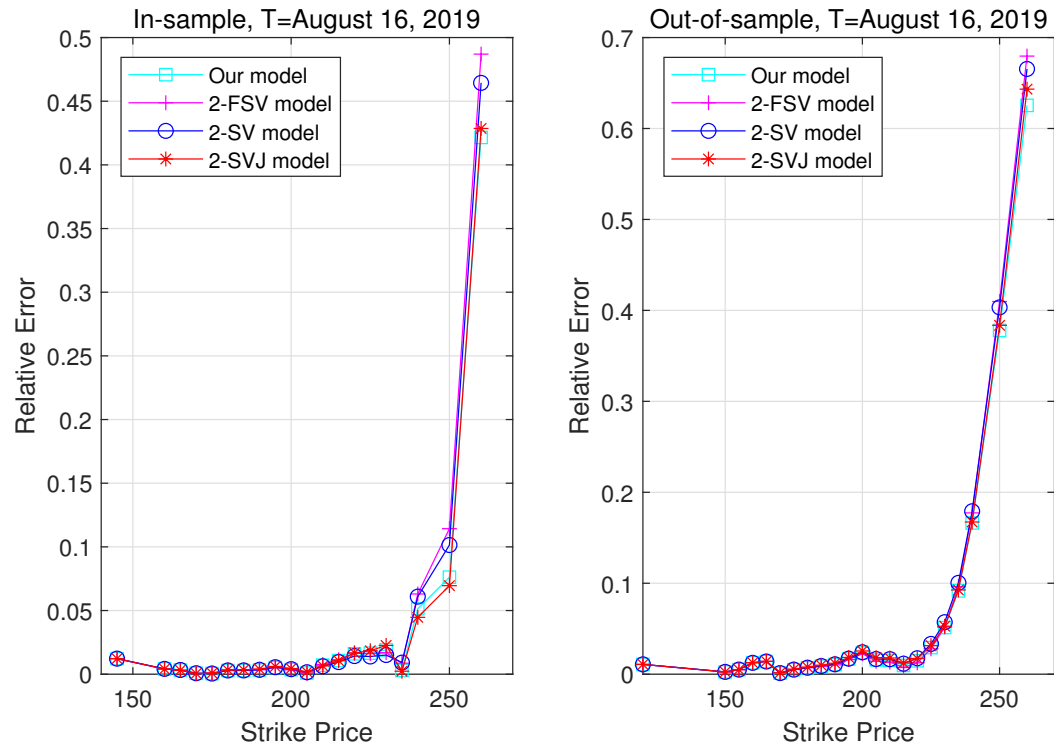

Figure 7. The comparison of predicted prices of four model specifications and market prices on 9 May 2019, with maturity $T=16$ August 2019 

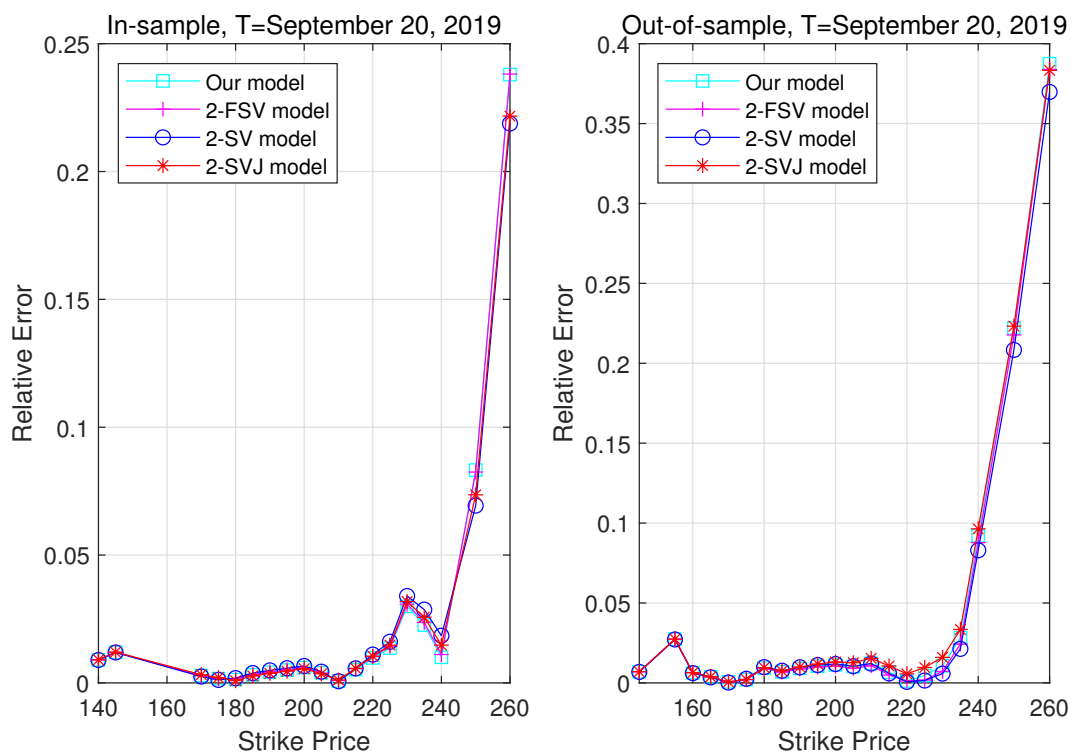

Figure 8. The comparison of predicted prices of four model specifications and market prices on 9 May 2019, with maturity $T=20$ September 2019.
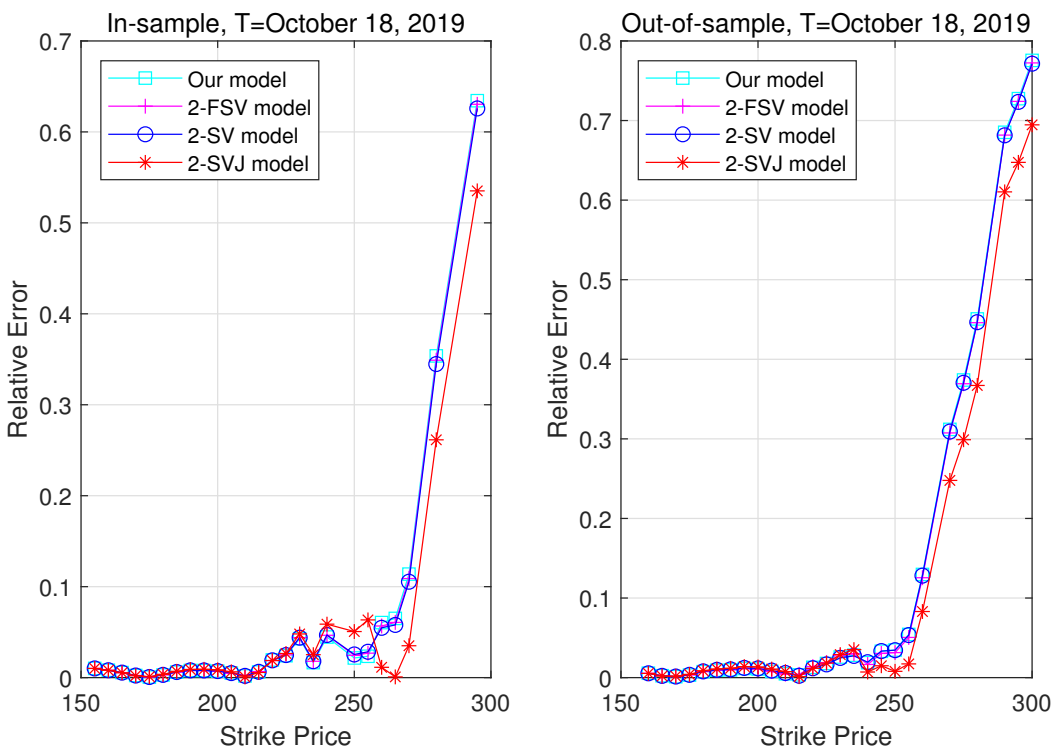

Figure 9. The comparison of predicted prices of four model specifications and market prices on 9 May 2019, with maturity $T=18$ October 2019. 

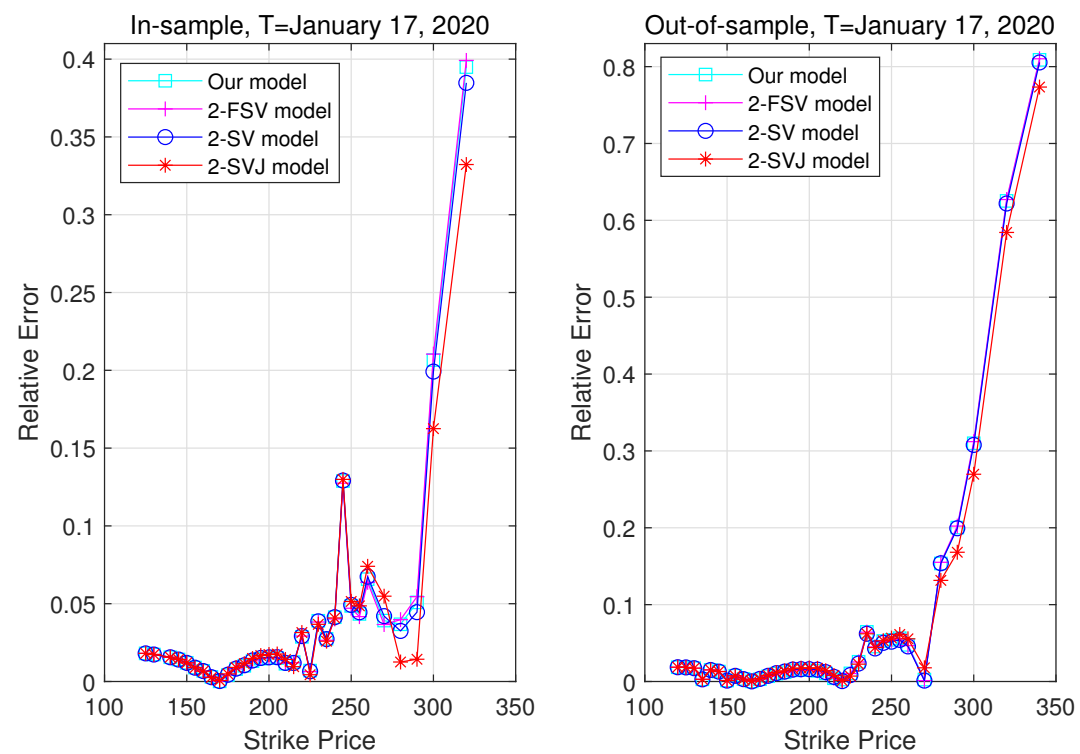

Figure 10. The comparison of predicted prices of four model specifications and market prices on 9 May 2019, with maturity $T=17$ January 2019.

To summarize the model calibration results, we also adopted the RMSE as a measure of the goodness of fit. Table 2 reports the out-of-sample pricing errors for the four models across different maturities. Note from Table 2 that our proposed model generally outperformed the other three models in terms of out-of-sample pricing errors. In fact, the same was true for in-sample, whose pricing errors were generally lower than those of the out-of-sample. We will not repeat them here. To measure the extent to which a model was better or worse than another, we defined the improvement rate as the relative differences between the pricing errors from the benchmark model and our proposed model, i.e.,

$$
\text { Improvement rate }=\frac{\text { RMSE }_{\text {benchmark }}-\mathrm{RMSE}_{\text {our }}}{\mathrm{RMSE}_{\text {benchmark }}} \times 100 \%
$$

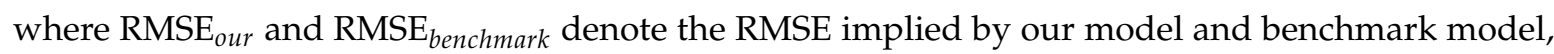
respectively. A positive (or negative) value of improvement rate meant that our model yielded lower (or higher) pricing errors than benchmark model, implying that the pricing performance of the former was better (or worse) than that of the latter by a percentage of that value.

From the last column of Table 2, we can see that our model was superior to the 2-SVJ model across different maturities, which meant that it was necessary to consider the market factor structure in equity option pricing. From the third last column of Table 2, the improvement rate indicated that our model slightly outperformed the 2-FSV model in terms of short term options, but was worse than that of both medium and long term. In spite of this, our empirical study presented here could at least illustrate that the equity option pricing model considering systematic and idiosyncratic volatility and jump risks may offer a good competitor of the models of Bates (2000), Christoffersen et al. (2009), or Christoffersen et al. (2018) for some other equity option markets. 
Table 2. Out-of-sample pricing errors. Note: This table shows the out-of-sample pricing errors across different maturities. Pricing errors are reported as the root mean squared errors (RMSE) of option prices for four models.

\begin{tabular}{cccccccc}
\hline RMSE & \multirow{2}{*}{ Our } & \multirow{2}{*}{ 2-FSV } & 2-SV & 2-SVJ & \multicolumn{2}{c}{ Improvement Rate } & \\
\cline { 1 - 3 } Maturity & & & & & Our vs. 2-FSV & Our vs. 2-SV & Our vs. 2-SVJ \\
\hline 24 May 2019 & 0.2573 & 0.2574 & 0.2596 & 0.2707 & $0.0373 \%$ & $0.8803 \%$ & $4.9568 \%$ \\
31 May 2019 & 0.2507 & 0.2508 & 0.2564 & 0.2652 & $0.0392 \%$ & $2.2499 \%$ & $5.4846 \%$ \\
7 June 2019 & 0.2343 & 0.2347 & 0.2527 & 0.2474 & $0.1764 \%$ & $7.2947 \%$ & $5.3044 \%$ \\
14 June 2019 & 0.1992 & 0.2041 & 0.2261 & 0.2099 & $2.4278 \%$ & $11.9155 \%$ & $5.0858 \%$ \\
21 June 2019 & 0.1824 & 0.1827 & 0.1873 & 0.1916 & $0.1399 \%$ & $2.5963 \%$ & $4.7934 \%$ \\
19 July 2019 & 0.3256 & 0.3301 & 0.3326 & 0.3383 & $1.3434 \%$ & $2.0948 \%$ & $3.7368 \%$ \\
16 August 2019 & 0.2856 & 0.2835 & 0.2879 & 0.2922 & $-0.7573 \%$ & $0.7946 \%$ & $2.2384 \%$ \\
20 September 2019 & 0.3177 & 0.3159 & 0.3162 & 0.3222 & $-0.5932 \%$ & $-0.4851 \%$ & $1.4002 \%$ \\
18 October 2019 & 0.1185 & 0.1180 & 0.1215 & 0.1272 & $-0.4458 \%$ & $2.4886 \%$ & $6.8593 \%$ \\
17 January 2020 & 0.4882 & 0.4882 & 0.4893 & 0.4943 & $-0.0071 \%$ & $0.2182 \%$ & $1.2201 \%$ \\
\hline
\end{tabular}

\section{Conclusions}

In Christoffersen et al. (2018), the issues of the equity volatility levels, skews, and term structures were investigated by using equity option prices and the principal component analysis method. Their empirical results indicated that the equity options had a strong factor structure, and then, they developed an equity option pricing model with a CAPM factor structure and stochastic volatility. In addition, jumps in stock returns of individual firms were triggered by either systematic events or idiosyncratic shocks. Some recent studies indicated that idiosyncratic jumps were a key important determinant of expected stock; see, for example, Xiao and Zhou (2018), Kapadia and Zekhnini (2019) and Bégin et al. (2020).

Motivated by these insights, we developed a novel model for pricing individual equity options that incorporated a market factor structure, which could be seen as a generalized version of the work by Christoffersen et al. (2018). Specifically, in our model, the individual equity prices were driven by the market factor, as well as an idiosyncratic component that also had stochastic volatility and jump. Due to our model belonging to the affine class, we derived the closed-form solutions for the prices of both the market index and individual equity options by utilizing the Fourier inversion. In addition, we provided the empirical results to test the pricing performance of our proposed factor model based on the S\&P 500 index and the AAPL stock on options. Toward this end, we empirically compared the pricing performance of our proposed model with those of the other three classical two factor stochastic volatility models being taken as benchmark models. The out-of-sample pricing performance of equity option valuation model considering market and idiosyncratic volatility and jump risks was significantly improved for short term and DOTM options. In conclusion, the empirical results presented here at least confirmed that the equity option pricing model considering systematic and idiosyncratic volatility and jump risks may offer as good competitor of the models of Bates (2000), Christoffersen et al. (2009), or Christoffersen et al. (2018) for some other option markets.

Funding: This work was supported by the National Natural Science Foundation of China (Grant No. 71901124) and the Natural Science Foundation of Jiangsu Province (Grant No. BK20190695).

Conflicts of Interest: The author declares no conflict of interest.

\section{References}

Andersen, Torben G., Nicola Fusari, and Viktor Todorov. 2015. The risk premia embedded in index options. Journal of Financial Economics 117: 558-84. [CrossRef]

Bakshi, Gurdip, Charles Cao, and Zhiwu Chen. 1997. Empirical performance of alternative option pricing models. Journal of Finance 52: 2003-49. [CrossRef] 
Bakshi, Gurdip, Nikunj Kapadia, and Dilip Madan. 2003. Stock return characteristics, skew laws, and the differential pricing of individual equity options. Review of Financial Studies 16: 101-43. [CrossRef]

Bakshi, Gurdip, and Nikunj Kapadia. 2003a. Delta-hedged gains and the negative market volatility risk premium. Review of Financial Studies 16: 527-66.

Bakshi, Gurdip, and Nikunj Kapadia. 2003b. Volatility risk premiums embedded in individual equity options: Some new insights. Journal of Derivatives 11: 45-54. [CrossRef]

Bardgett, Chris, Elise Gourier, and Markus Leippold. 2019. Inferring volatility dynamics and risk premia from the S\&P 500 and VIX markets. Journal of Financial Economics 131: 593-618. [CrossRef]

Bates, David S. 1996. Jumps and stochastic volatility: Exchange rate processes implicit in Deutsche mark options. Review of Financial Studies 9: 69-107. [CrossRef]

Bates, David S. 2000. Post-'87 crash fears in the S\&P 500 futures option market. Journal of Econometrics 94: 181-238. [CrossRef]

Broadie, Mark, Mikhail Chernov, and Michael Johannes. 2007. Model specification and risk premia: Evidence from futures options. Journal of Finance 62: 1453-90. [CrossRef]

Bégin, Jean-François, Christian Dorion, and Geneviève Gauthier. 2020. Idiosyncratic jump risk matters: Evidence from equity returns and options. Review of Financial Studies 33: 155-211.

Carr, Peter, and Dilip B. Madan. 2012. Factor models for option pricing. Asia-Pacific Financial Markets 19: 319-29. [CrossRef]

Cheang, Gerald H. L., Carl Chiarella, and Andrew Ziogas. 2013. The representation of American options prices under stochastic volatility and jump-diffusion dynamics. Quantitative Finance 13: 241-53. [CrossRef]

Cheang, Gerald H. L., and Len Patrick Dominic M. Garces. 2019. Representation of exchange option prices under stochastic volatility jump-diffusion dynamics. Quantitative Finance. [CrossRef]

Christoffersen, Peter, Kris Jacobs, and Chayawat Ornthanalai. 2012. Dynamic jump intensities and risk premiums: Evidence from S\&P 500 returns and options. Journal of Financial Economics 106: 447-72.

Christoffersen, Peter, Mathieu Fournier, and Kris Jacobs. 2018. The factor structure in equity options. Review of Financial Studies 31: 595-637. [CrossRef]

Christoffersen, Peter, Steven Heston, and Kris Jacobs. 2009. The shape and term structure of the index option smirk: Why multifactor stochastic volatility models work so well. Management Science 55: 1914-32. [CrossRef]

Duffie, Darrell, Jun Pan, and Kenneth Singleton. 2000. Transform analysis and asset pricing for affine jump diffusions. Econometrica 68: 1343-76. [CrossRef]

Eraker, Biørn, Miichael Johannes, and Nicholas Polson. 2003. The Impact of Jumps in Volatility and Returns. Journal of Finance 58: 1269-1300. [CrossRef]

Fouque, Jean-Pierre, and Adam P. Tashman. 2012. Option pricing under a stressed-beta model. Annals of Finance 8: 183-203. [CrossRef]

Fouque, Jean-Pierre, and Eli Kollman. 2011. Calibration of stock betas from skews of implied volatilities. Applied Mathematical Finance 18: 119-37. [CrossRef]

Kapadia, Nishad, and Morad Zekhnini. 2019. Do idiosyncratic jumps matter? Journal of Financial Economics 131: 666-92. [CrossRef]

Kou, Steven G. 2002. A jump-diffusion model for option pricing. Management Science 48: 1086-101. [CrossRef]

Merton, Robert C. 1976. Option pricing when underlying stock returns are discontinuous. Journal of Financial Economics 3: 125-44. [CrossRef]

Wong, Hoi Ying, Edwin Kwan Hung Cheung, and Shiu Fung Wong. 2012. Lévy betas: Static hedging with index futures. Journal of Futures Markets 32:1034-59. [CrossRef]

Xiao, Xiao, and Chen Zhou. 2018. The decomposition of jump risks in individual stock returns. Journal of Empirical Finance 47: 207-28.

(C) 2020 by the author. Licensee MDPI, Basel, Switzerland. This article is an open access article distributed under the terms and conditions of the Creative Commons Attribution (CC BY) license (http:/ / creativecommons.org/licenses/by/4.0/). 